\title{
Content analysis of clinical indicators for Impaired gas exchange
}

\author{
Análise de conteúdo dos indicadores clínicos para Troca de gases prejudicada \\ Análisis de contenido de indicadores clínicos para Deterioro del intercambio gaseoso
}

\section{Lívia Maia Pascoal ${ }^{a}$ Marcos Venícios de Oliveira Lopes ${ }^{b}$ Viviane Martins da Silva ${ }^{b}$ Camila Maciel Diniz ${ }^{b}$ Marília Mendes Nunes ${ }^{b}$ Vanessa Emille Carvalho de Sousa Freire ${ }^{b}$ Beatriz Beltrão Amorim ${ }^{c}$}

\section{How to cite this article:} Pascoal LM, Lopes MVO, Silva VM, Diniz CM, Nunes MM, Freire VECS, Amorim BB. Content analysis of clinical indicators for Impaired gas exchange. Rev Gaúcha Enferm. 2021;42:e20200099. doi: https://doi.org/10.1590/19831447.2021.20200099 a Universidade Federal do Maranhão (UFMA), Centro de Ciências Sociais, Saúde e Tecnologia, Curso de Enfermagem. Imperatriz, Maranhão, Brasil.

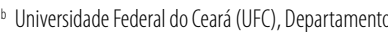
de Enfermagem. Fortaleza, Ceará, Brasil.

Hospital Universitário Walter Cantídio (HUWC) Fortaleza, Ceará, Brasil.

\section{ABSTRACT}

Objective: To analyze the relevance of clinical indicators and the clarity and precision of conceptual and operational definitions of the diagnosis Impaired gas exchange.

Methods: Content analysis, by 39 nurse judges, divided into the phases of conceptual definition of the phenomenon of interest, construction of the structure of the phenomenon of interest and analysis of the judges on the built structure.

Results: From the 22 indicators, 21 were considered relevant Impaired gas exchange. The indicators that obtained absolute relevance were Cyanosis, Hypercapnia, Hypoxemia and Tachycardia. The indicator Headache upon waking did not show any statistically significant relevance for the diagnosis. All conceptual and operational definitions were clear and precise.

Conclusion: The indicators listed for Impaired gas exchange were relevant to the phenomenon, except Headache upon waking because it does not correspond to a safe manifestation to identify the diagnosis, according to the analysis of the judges. Each conceptual and operational definition was adequate for its indicator.

Keywords: Nursing diagnosis. Validation study. Content validation. Pulmonary gas exchange.

\section{RESUMO}

Objetivo: Analisar a relevância dos indicadores clínicos e a clareza e precisão das definições conceituais e operacionais do diagnóstico Troca de gases prejudicada.

Métodos: Análise de conteúdo, por 39 juízes enfermeiros, dividida nas fases de definição conceitual do fenômeno de interesse, construção da estrutura do fenômeno de interesse e análise dos juízes sobre a estrutura construída.

Resultados: Dos 22 indicadores, 21 foram considerados relevantes Troca de gases prejudicada. Os indicadores que obtiveram relevância absoluta foram Cianose, Hipercapnia, Hipoxemia e Taquicardia. 0 indicador Cefaleia ao acordar não apresentou relevância estatisticamente significante para o diagnóstico. Todas as definiç̧ões conceituais e operacionais foram claras e precisas.

Conclusão: 0 s indicadores elencados para Troca de gases prejudicada foram relevantes ao fenômeno, exceto Cefaleia a a acordar pois não corresponde a uma manifestação segura para identificar o diagnóstico, conforme a análise dos juízes. Cada definição conceitual e operacional foi adequada para seu referido indicador.

Palavras-chave: Diagnóstico de enfermagem. Estudo de validação. Troca gasosa pulmonar.

\section{RESUMEN}

Objetivo: Analizar la relevancia de los indicadores clínicos y la claridad y precisión de las definiciones conceptuales y operativas del diagnóstico Deterioro del intercambio gaseoso.

Métodos: Análisis de contenido, realizado por 39 jueces enfermeros, dividido en las fases de definición conceptual del fenómeno de interés, construcción de la estructura del fenómeno de interés y análisis de los jueces sobre la estructura construida.

Resultados: De los 22 indicadores, 21 fueron considerados relevantes Deterioro del intercambio gaseoso. Los indicadores que obtuvieron relevancia absoluta fueron Cianosis, Hipercapnia, Hipoxemia y Taquicardia. El indicador Cefalea al despertar no mostró relevancia estadísticamente significativa para el diagnóstico. Todas las definiciones conceptuales y operativas fueron claras y precisas. Conclusión: Los indicadores enumerados para Deterioro del intercambio gaseoso fueron relevantes para el fenómeno, excepto Cefalea al despertar porque no corresponde a una manifestación segura para identificar el diagnóstico, según el análisis de los jueces. Cada definición conceptual y operativa fue adecuada para su indicador.

Palabras clave: Diagnóstico de enfermería. Estudio de validación. Intercambio gaseoso pulmonar. 


\section{口INTRODUCTION}

The respiratory impairment due to pulmonary infections such as acute respiratory syndromes - Severe acute respiratory syndrome (SARS), Middle East respiratory syndrome (MERS) and Coronavirus disease 2019 (COVID-19) - leads to clinical manifestations described among nursing phenomena, in particular the diagnosis Impaired gas exchange (IGE), such as abnormal breathing pattern, hypoxemia and hypercapnia ${ }^{(1)}$. Such clinical indicators are part of a spectrum of severity of these diseases ${ }^{(1)}$, which need to be identified early in order to reduce the time between diagnostic inference and decision making.

The occurrence of acute respiratory infection has a worldwide epidemiological importance, considering the epidemic situations faced in 2002 and 2012 - SARS and MERS, respectively ${ }^{(2)}$, and the current situation of the COVID-19 pandemic with more than 200,000 cases worldwide, only in the first quarter of $2020^{(3)}$. In view of this scenario, it is necessary to use tools that can assist in the early identification of signs indicating respiratory impairment, manifested with a human response. One of these tools is nursing taxonomies, in particular NANDA International (NANDA-I), Inc. ${ }^{(4)}$ which encompasses human responses as nursing diagnoses.

However, some inconsistencies within the taxonomy are observed, such as the absence of others of clinical indicators relevant to the diagnosis, similar clinical indicators or nursing diagnoses that share the same set of elements, which may lead to doubts during the diagnostic inference. In this sense, the IGE diagnosis stands out, which is similar to other nursing phenomena such as Ineffective airway clearance (IAC) and Ineffective breathing pattern (IBP), as evidenced in the literature ${ }^{(5)}$. To reduce such problem, it is important to know the clinical indicators that are related to the phenomenon of interest, with emphasis on their conceptual and operational definitions in order to facilitate the correct identification by the nurse during the clinical reasoning process.

In addition to enabling a structure more consistent with the IGE diagnosis, conducting validation studies on this phenomenon is necessary, given the possibility of excluding IGE in the next version of the taxonomy, if studies that prove its validity are not performed. Thus, the permanence of the diagnosis in NANDA-I needs to be sustained, considering its occurrence in different clinical settings, as evidenced in the literature ${ }^{(5-7)}$. By using a taxonomy that directs to planning and nursing care, nurses will more easily identify, in clinical practice, the causal factors and clinical indicators that suggest impaired gas exchange.
One way to reduce such inconsistencies is to submit the nursing diagnosis to a process of careful analysis of its elements and their respective definitions with the help of specialist nurses in the topic of interest, who will analyze the relevance of clinical indicators for the phenomenon, as well as the adequacy of their conceptual and operational definitions. Thus, to guide the present study, the following questions were asked:"What clinical indicators represent the phenomenon of nursing IGE, according to the assessment of nurses who are experts in the subject?" and "Are the conceptual and operational definitions of the clinical indicators of IGE properly clear and precise?". Thus, the study aimed to analyze the relevance of clinical indicators and the clarity and precision of the conceptual and operational definitions of the Impaired gas exchange diagnosis. The study was carried out according to the proposal to develop content validation studies based on the assessment of the relevance of the concepts based on the opinion of experts, using statistical methods to assess the accuracy of the estimates ${ }^{(8)}$.

\section{$\square$ METHODS}

The present study consists by the second stage of the validation of the IGE diagnosis, which was previously submitted to a simultaneous concept analysis ${ }^{(9)}$ to two other respiratory nursing diagnoses - IBP and IAC. Three stages were used to build the content analysis, namely: conceptual definition of the phenomenon of interest, structuring the phenomenon of interest, and analysis of the content of the phenomenon of interest ${ }^{(8)}$. The study was carried out between December 2014 and February 2015, in a capital city of northeastern Brazil, after approval by the ethics and research committee with a certification number (CAAE) 31230914,1,0000,5054 and under the statement number 779,003 .

The first stage, carried out along with the first phase of the study (simultaneous concept analysis), consisted by a refined search in the literature on the concepts involved in the IGE phenomenon, which was carried out in December 2014. For this, were chosen the databases LILACS, Scopus, CINAHL, and the PubMed portal. The controlled descriptor pulmonary gas exchange was used, respecting the DeCS and MeSH nomenclature. The searches were guided by the questions "What are the signs and symptoms associated with the phenomenon of interest IGE?" and "How can these manifestations be defined and measured?".

The inclusion criteria of the studies were: to contemplate the analyzed concept (pulmonary gas exchange), availability in English, Portuguese or Spanish, and consistency to the 
guiding questions. The search initially totaled, after using the descriptor, in 2545 findings on the Pubmed portal, 176 on the LILACS database, 15015 on Scopus and 2075 CINAHL. After reading the title and abstract, 15 articles from the LILACS database remained, 20 from Pubmed, 25 from Scopus and five from CINAHL. These were submitted to full reading, selecting at the end seven studies from the LILACS database, nine from the Pubmed portal and four studies from each database, Scopus and CINAHL. The final sample resulted in five studies, being two from the Pubmed portal, two from the CINAHL database and one from the Lilacs database.

After the studies selection, a consensus group was created, with the participation of three nurses with a minimum master's degree and experience in developing research and publications on nursing diagnoses, especially respiratory diagnoses. This group was created to establish the clinical indicators relevant to the IGE phenomenon, as well as their respective conceptual and operational definitions. To guide this stage, the group made use of the question "What clinical indicators are related to the nursing phenomenon IGE and how are these elements defined and measured?"

After surveying the clinical indicators of the IGE diagnosis in the literature, the concepts of the phenomenon of interest were structured, constituting the second stage of the content analysis study ${ }^{(10)}$. Eight clinical indicators have been identified in the literature. During the analysis of the consensus group, another 14 indicators were incorporated into the IGE. Among these, one indicator (Changes in respiratory rate) was divided into two (Bradypnea and Tachypnea) and the indicator Altered arterial blood gases was excluded because it had a similar meaning to other indicators (Decreased carbon dioxide, Hypercapnia, Hypoxemia). Thus, the final list included 22 clinical indicators, namely: Nose wing flick, Headache upon waking, Cyanosis, Confusion, Abnormal skin color (pale, darkened), Diaphoresis, Decreased carbon dioxide, Dyspnea, Visual disturbances, Hypercapnia, Hypoxemia, Decreased oxygen saturation, Hypoxia, Restlessness, Irritability, Abnormal arterial pH, Tachypnea, Bradypnea, Changes in respiratory rhythm, Changes in respiratory depth, Drowsiness, and Tachycardia.

Thus, all clinical indicators identified in the literature, as well as the defining characteristics present in the NANDA-I taxonomy ${ }^{(4)}$, were organized and described, conceptually and empirically, according to the group of nurses. It is worth mentioning that the terms defining characteristic and clinical indicators were treated as synonyms in the present study, as they refer to the clinical manifestations of the phenomenon under study.
The last stage of assessment of the IGE phenomenon consisted by the analysis of these clinical indicators by judg$\mathrm{es}^{(10)}$. This stage took place between January and February 2015. The relevance of each indicator for the occurrence of the phenomenon was assessed, as well as its conceptual and operational definitions. The selection of judges considered a set of essential attributes, as recommended ${ }^{(11)}$. The selection criteria were to present theoretical and/or clinical experience of at least five years with the theme under study and/or population at risk for the diagnosis and/or nursing taxonomies. Thus, nurses were sought through the curriculum on the Lattes platform, as well as members of research groups on nursing diagnoses and/or theme of the phenomenon of interest - IGE. Additionally, the non-probabilistic sampling strategy ("snowball sampling") was used to obtain new judges by indicating the previously invited evaluators ${ }^{(12)}$.

The sample calculation was based on the statistical criteria of a minimum proportion (P) of $85 \%$ of agreement regarding the relevance of each clinical indicator evaluated, and the difference (e) of $12 \%$ in relation to this agreement, including an interval of $73 \%$ to $97 \%$. Thus, the formula $n=\mathbf{Z}_{a}{ }^{2} \cdot \mathbf{P .}(\mathbf{1}-\mathbf{P}) / \mathbf{e}^{\mathbf{2}}$ was applied, using as the significance level (Z $\mathbf{Z})$ $95 \%$. Substituting the values in that formula, the sample resulted in a minimum number of 35 judges. The data collection process took place after the consent form was given, which was sent via email to the judges. Initially, 54 judges agreed to participate in the study, however, after the period of 30 days stipulated for returning the material, only 39 judges contemplated the final sample.

The contact with the judges was made electronically, through which the consent form was sent to participate in the research and the data collection instrument. After the agreement and signature of the Free and Informed Consent Form (FICF), the judges were organized into two groups, one considering the assistance/clinical experience and the other the theoretical/academic experience of the judges.

The collection instrument was organized in two sections: judge's identification data, including academic title and production, and information on clinical indicators of IGE. For these, the criteria of relevance for the occurrence of the diagnosis under study were considered, the clarity and precision of conceptual and operational definitions. The relevance refers to the cohesion and coherence of the indicators to manifest the IGE diagnosis. The definitions'clarity consists by the ability of understanding such definitions to present the indicator in a conceptual and operational way, using short phrases and clear expressions. Precision, in turn, refers to the ability of the definition to differentiate 
clinical indicators, enabling their clinical characterization. The evaluations of the judges on the indicators were made in a dichotomous way, in adequate or inadequate. That is, each clinical indicator was considered relevant or not for IGE, as well as each conceptual and operational definition was considered clear or not clear and precise or not precise. In addition, the judges were able to suggest adjustments in the definition's writing, even if their judgment was positive for the clarity and precision of the evaluated definition.

The collected information was organized in a spreadsheet in the Excel 2010 program and analyzed with the support of the statistical package SPSS version 21.0 and the software $R$ version 2.12.1. The characterization of nurse judges was made using descriptive statistics, with the obtaining of absolute, percentage, mean and median values. The analysis of clinical indicators for relevance, clarity and precision was carried out using the binomial test. This test made it possible to verify whether the proportion of judges who judged the item appropriate was greater than or equal to $85 \%$ (CVl>0.85). Thus, the indicator was considered relevant when it presented a $p$-value $>0.05$. The same value was applied to consider the definitions of each indicator clear and precise. In addition, the global content validity index (CVI) was calculated, based on the average of the proportions of the items identified as relevant by the evaluators when the binomial test was applied in isolation for each clinical indicator.

\section{RESULTS}

\section{Judges Profile}

The study had the participation of 39 judges, 22 nurses with experience in research and 17 nurses with experience in care practice. The sample presented a female majority (94.9\%), with an average age of 33 years (SD 7.4) and an average formation time of 9.28 (SD 7.1). The geographic profile included, mainly, the Northeast (64.1\%), Southeast (25.7\%), South (5.1\%) and Midwest (5.1\%) regions. With regard to professional data, the majority had a Master's degree (57.9\%), with a current occupation in Nursing Assistance (59\%), with a double working day - Assistance and Educational Institution (41\%). Regarding the theme under study, $76.9 \%$ of the judges participate or have participated in study groups on nursing terminology, $79.5 \%$ developed studies on nursing terminology, $64.1 \%$ studied respiratory nursing diagnoses and $66.7 \%$ have developed studies on respiratory changes. Nursing care for patients with respiratory disorders or with respiratory nursing diagnoses was manifested by $94.9 \%$ of participants.

\section{Analysis of clinical indicators of IGE}

The judges'answers on the relevance of clinical indicators for IGE are shown in table 1.22 indicators were evaluated and from these, 21 were considered relevant for the referred diagnosis. The indicators that obtained absolute relevance among the judges were Cyanosis, Hypercapnia, Hypoxemia and Tachycardia. In addition, it is important to highlight that the other indicators also demonstrated suitability for use in diagnostic inference processes of IGE, except Headache upon waking. This indicator was not considered adequate for the diagnosis under study, according to the judges' assessments $(p=0.002)$.

The judges' outcomes, regarding the criteria of clarity and precision, for the conceptual and empirical definitions of the clinical indicators proposed for the IGE diagnosis showed that all the items evaluated were considered adequate (Table 2). However, in order to make some conceptual definitions or empirical references more appropriate, suggestions were made for the writing of these definitions, such as changing the term "experimented sensation of breathing" by the term "sensation of the act of breathing" in the conceptual definition of the element Dyspnea.

\section{DISCUSSION}

The respiratory system impairment as a result of an infectious process, for example, triggers compensatory mechanisms to reestablish the balance between pulmonary gas exchanges. However, when such mechanisms are not sufficient, either due to pre-existing clinical conditions (comorbidities) or due to the particularities of the individual (age), clinical complications can be evidenced, such as high blood levels of carbon dioxide, cyanosis, hypoxemia and tachycardia. Such indicators were considered relevant in the present study by all of the judges' assessment.

In respiratory syndromes faced in pandemics, such as SARs-CoV2, which causes COVID-19, these clinical indicators have been described ${ }^{(13)}$. Hypercapnia cases have been associated with low tidal volume during mechanical ventilation in patients with acute respiratory syndrome due to infection by the new coronavirus(14). In addition, radiological findings indicate severe pulmonary involvement among these patients, showing pulmonary infiltrates that compromise respiratory functions and impair gas exchange, which is evidenced by hypoxia ${ }^{(15)}$

The clinical indicator Cyanosis, despite being listed in the taxonomy as a unique defining characteristic, was considered by the judges as included in the Abnormal skin 
Table 1 - Judges'analysis of the relevance of clinical indicators of nursing diagnosis Impaired gas exchange. Fortaleza, CE, 2015

\begin{tabular}{|c|c|c|c|}
\hline \multirow{3}{*}{$\begin{array}{c}\text { Variables } \\
\text { Clinical Indicators }\end{array}$} & \multicolumn{3}{|c|}{ IGE Diagnostic } \\
\hline & \multicolumn{3}{|c|}{ Relevance } \\
\hline & $\mathbf{n}$ & $\%$ & P-value* \\
\hline Cyanosis $^{2}$ & 38 & 100.0 & 1.000 \\
\hline Hypercapnia' ${ }^{1}$ & 39 & 100.0 & 1.000 \\
\hline Hypoxemia & 39 & 100.0 & 1.000 \\
\hline Tachycardia' & 39 & 100.0 & 1.000 \\
\hline Abnormal arterial $\mathrm{pH}^{1}$ & 38 & 97.4 & 0.998 \\
\hline Tachypnea ${ }^{2}$ & 38 & 97.4 & 0.998 \\
\hline Dyspnea ${ }^{1}$ & 36 & 97.3 & 0.997 \\
\hline Decreased oxygen saturation ${ }^{2}$ & 37 & 94.9 & 0.986 \\
\hline Restlessness $^{1}$ & 37 & 94.9 & 0.986 \\
\hline Decreased carbon dioxide ${ }^{1}$ & 35 & 94.6 & 0.981 \\
\hline Hypoxia $^{1}$ & 36 & 92.3 & 0.945 \\
\hline Nose wing flick ${ }^{1}$ & 35 & 89.7 & 0.856 \\
\hline Diaphoresis $^{2}$ & 35 & 89.7 & 0.856 \\
\hline Changes in respiratory rate ${ }^{2}$ & 35 & 89.7 & 0.856 \\
\hline Confusion ${ }^{1}$ & 34 & 87.2 & 0.715 \\
\hline Irritability ${ }^{1}$ & 34 & 87.2 & 0.715 \\
\hline Changes in respiratory depth ${ }^{2}$ & 34 & 87.2 & 0.715 \\
\hline Bradypnea $^{2}$ & 33 & 84.6 & 0.541 \\
\hline Abnormal skin color (pale, darkened) ${ }^{1}$ & 32 & 84.2 & 0.514 \\
\hline Drowsiness $^{1}$ & 31 & 81.6 & 0.341 \\
\hline Visual disturbances $^{2}$ & 29 & 74.4 & 0.057 \\
\hline Headache upon waking ${ }^{1}$ & 25 & 65.8 & 0.002 \\
\hline
\end{tabular}

Source: Research data, 2015

'Defining characteristics of NANDA-l; ${ }^{2}$ Clinical indicators identified by the literature review. " $p>0.05$, Binomial test. 
Pascoal LM, Lopes MVO, Silva VM, Diniz CM, Nunes MM, Freire VECS, Amorim BB

Table 2 - Judges' analysis regarding the criteria of clarity and precision for conceptual definitions and empirical references of clinical indicators of nursing diagnosis Impaired gas exchange. Fortaleza, CE, 2015

\begin{tabular}{|c|c|c|c|c|c|c|c|c|c|c|c|c|}
\hline \multirow{3}{*}{$\begin{array}{c}\text { Variables } \\
\text { Clinical Indicators }\end{array}$} & \multicolumn{6}{|c|}{ Conceptual definition } & \multicolumn{6}{|c|}{ Empirical reference } \\
\hline & \multicolumn{3}{|c|}{ Clarity } & \multicolumn{3}{|c|}{ Precision } & \multicolumn{3}{|c|}{ Clarity } & \multicolumn{3}{|c|}{ Precision } \\
\hline & $\mathbf{n}$ & $\%$ & Value $p^{\dagger}$ & $\mathbf{n}$ & $\%$ & Value $\mathbf{p}^{\dagger}$ & $\mathbf{n}$ & $\%$ & Value $\mathbf{p}^{\dagger}$ & $\mathbf{n}$ & $\%$ & Value $p^{\dagger}$ \\
\hline Decreased $\mathrm{O}_{2}$ saturation $^{2 *}$ & 39 & 100.0 & 1.000 & 38 & 97.4 & 0.998 & 38 & 97.4 & 0.998 & 35 & 92.1 & 0.938 \\
\hline Changes in respiratory rate ${ }^{2 *}$ & 39 & 100.0 & 1.000 & 38 & 97.4 & 0.998 & 37 & 94.9 & 0.986 & 33 & 84.6 & 0.541 \\
\hline Changes in respiratory depth ${ }^{2 *}$ & 39 & 100.0 & 1.000 & 38 & 97.4 & 0.998 & 33 & 84.6 & 0.541 & 34 & 87.2 & 0.715 \\
\hline Tachycardia $^{1 *}$ & 39 & 100.0 & 1.000 & 37 & 94.9 & 0.986 & 39 & 100.0 & 1.000 & 35 & 92.1 & 0.938 \\
\hline Diaphoresis $^{2}$ & 38 & 100.0 & 1.000 & 35 & 92.1 & 0.938 & 38 & 100.0 & 1.000 & 36 & 94.7 & 0.984 \\
\hline Dyspnea ${ }^{1 *}$ & 38 & 100.0 & 1.000 & 38 & 97.4 & 0.998 & 39 & 100.0 & 1.000 & 38 & 97.4 & 0.998 \\
\hline Hypercapnia $^{1 *}$ & 38 & 100.0 & 1.000 & 38 & 97.4 & 0.998 & 38 & 100.0 & 1.000 & 35 & 92.1 & 0.938 \\
\hline Abnormal arterial $\mathrm{pH}^{1 *}$ & 38 & 100.0 & 1.000 & 37 & 94.9 & 0.986 & 39 & 100.0 & 1.000 & 39 & 100.0 & 1.000 \\
\hline Cyanosis $^{2 *}$ & 38 & 97.4 & 0.998 & 39 & 100.0 & 1.000 & 38 & 97.4 & 0.998 & 38 & 97.4 & 0.998 \\
\hline Confusion $^{1 *}$ & 38 & 97.4 & 0.998 & 36 & 92.3 & 0.945 & 37 & 94.9 & 0.986 & 36 & 92.3 & 0.945 \\
\hline Hypoxia ${ }^{2 *}$ & 38 & 97.4 & 0.998 & 37 & 94.9 & 0.986 & 37 & 94.9 & 0.986 & 36 & 92.3 & 0.945 \\
\hline Restlessness ${ }^{1 *}$ & 38 & 97.4 & 0.998 & 36 & 92.3 & 0.945 & 38 & 97.4 & 0.998 & 37 & 94.9 & 0.986 \\
\hline Tachypnea $^{2}$ & 38 & 97.4 & 0.998 & 38 & 97.4 & 0.998 & 38 & 97.4 & 0.998 & 36 & 92.3 & 0.945 \\
\hline Bradypnea ${ }^{2 *}$ & 38 & 97.4 & 0.998 & 38 & 97.4 & 0.998 & 36 & 92.3 & 0.945 & 34 & 87.2 & 0.715 \\
\hline Abnormal skin color (pale, darkened) ${ }^{1}$ & 37 & 97.4 & 0.997 & 36 & 94.7 & 0.984 & 36 & 94.7 & 0.984 & 35 & 92.1 & 0.938 \\
\hline Nose wing flick ${ }^{1 *}$ & 37 & 94.9 & 0.986 & 38 & 97.4 & 0.998 & 37 & 94.9 & 0.986 & 38 & 97.4 & 0.998 \\
\hline Headache upon waking ${ }^{1}$ & 37 & 94.9 & 0.986 & 33 & 86.8 & 0.693 & 34 & 87.2 & 0.715 & 30 & 76.9 & 0.120 \\
\hline Hypoxemia $^{1 *}$ & 37 & 94.9 & 0.986 & 36 & 94.7 & 0.984 & 37 & 94.9 & 0.986 & 35 & 89.7 & 0.856 \\
\hline |rritability ${ }^{1 *}$ & 37 & 94.9 & 0.986 & 35 & 89.7 & 0.856 & 37 & 94.9 & 0.986 & 36 & 94.7 & 0.984 \\
\hline Decreased carbon dioxide ${ }^{1 *}$ & 36 & 97.3 & 0.997 & 34 & 94.4 & 0.978 & 36 & 100.0 & 1.000 & 34 & 94.4 & 0.978 \\
\hline Visual disturbances ${ }^{2 *}$ & 36 & 97.3 & 0.997 & 32 & 86.5 & 0.669 & 35 & 92.1 & 0.938 & 33 & 86.8 & 0.693 \\
\hline Drowsiness ${ }^{1 *}$ & 36 & 92.3 & 0.945 & 35 & 89.7 & 0.856 & 33 & 86.8 & 0.693 & 35 & 89.7 & 0.856 \\
\hline
\end{tabular}

Source: Research data, 2015

'Defining characteristics of NANDA-1; ${ }^{2}$ Clinical indicators identified by the literature review. "Definitions modified after judges' analysis. ${ }^{p} p>0.05$, Binomial Test.

Rev Gaúcha Enferm. 2021:42:e20200099 
color indicator. This, in turn, although relevant to IGE, was subjected to some questions by the judges. For example, the judges pointed out that pallor would not be as specific as the changes associated with red blood cell deoxygenation, such as Cyanosis, for the inference of IGE. In this sense, the Cyanosis indicator becomes important, as it suggests complexity of clinical respiratory conditions, such as those found in critically ill patients affected by COVID-19 $9^{(16)}$.

Thus, evaluating the presence of these indicators in a specific population may help inference about the relationship between these manifestations and the diagnosis itself, as observed in a study ${ }^{(6)}$ about clinical prognosis of IGE in children with acute respiratory infection (ARI). This study showed the change in skin color as an important sign for the development of the diagnosis. With that, the presence of the Abnormal skin color indicator leads to a worse prognosis when IGE occurs. The study also estimated that the children evaluated in the study have a $54 \%$ chance of presenting the Abnormal skin color indicator.

In addition, corroborating the findings of this research, a study ${ }^{(15)}$ validated the Abnormal skin color characteristic for the diagnosis of IGE, although it was considered secondary in the judges' assessment (score $=0.79$ ). About this, the aforementioned authors inferred that, in some situations of clinical practice, the nurse does not value evidence that can support the diagnostic hypothesis. Based on these considerations, it is suggested to merge the indicators into a single element, Abnormal skin color, and it is hoped that the clinical validation stage can confirm, or not, the relevance of this indicator for the inference of IGE.

With similar behavior to the Altered skin color, Hypoxemia also showed an important relationship with IGE. The complete agreement among the judges regarding the relevance of Hypoxemia as a strong indicator for the occurrence of the diagnosis under study was also evidenced in a pediatric population with ARI. In this scenario, the study showed that the occurrence of Hypoxemia led to a 135 times greater chance of manifesting IGE when compared to those children without the referred indicator ${ }^{(6)}$. In addition, another scenario of Hypoxemia manifestation was among severe patients affected with COVID-19(17-18). These patients presented the referred indicator in a critical clinical condition of the disease, in which the most severe Hypoxemia was statistically related to Dyspnea ${ }^{(18)}$. Such fact can be justified due to the accumulation of pulmonary secretions commonly manifested in respiratory infectious conditions. Thus, it favors the occurrence of atelectasis, leading to losses in the gas exchange process. Thus, it commits itself to obtain oxygen, while the excretion of carbon dioxide decreases, occurring its accumulation in the bloodstream and the oxygen reduction ${ }^{(19)}$.
The relevance of the Tachycardia indicator, although it was considered important for the inference of IGE, needs to be viewed with caution, since previous clinical validation studies did not present high values for the occurrence of this indicator in children with AR( ${ }^{(5-7)}$. Additionally, in a study on diagnostic differentiation between respiratory nursing diagnoses - IBP, IAC and IGE ${ }^{(5)}$, tachycardia was not among the most accurate indicators to predict the occurrence of one of these diagnoses. In other words, Tachycardia was considered an indicator of IGE, but it did not fit among those indicators that serve as key elements in the differentiation between IGE, AIC and IBP(5). Thus, although tachycardia is observed in patients with respiratory impairment, as a compensatory mechanism, this may not be a reliable indicator for inferring IGE.

Other indicators, although considered also relevant by most of the judges, should be identified with caution during the diagnostic inference of IGE. It was the case of the clinical indicator Headache upon waking that, despite being described in the NANDA-I taxonomy ${ }^{(4)}$ as a manifestation for IGE, its observation does not represent a good indicator for the diagnostic inference of IGE and, therefore, should be taken out from the NANDA-I classification ${ }^{(4)}$. This is because headache upon waking is a symptom that can occur due to situations related to hypoxia and hypoxemia, which indicate impaired gas exchange. The literature reports that such changes result in dilation of brain vessels, especially arteries and arterioles, which could explain the presence of headache ${ }^{(20-21)}$. Morning headache has been frequently reported in patients with COPD and Obstructive sleep apnea ${ }^{(22-23)}$.

Although patients with impaired gas exchange could present headache as a clinical manifestation, the judges reported the difficulty in evaluating it in clinical practice in pediatric patients, sedated or with neurological problems. They also pointed out that, even in these cases, the impaired gas exchange diagnosis could be identified with the help of the other proposed indicators. A similar result was pointed out in the study ${ }^{(24)}$, which aimed to validate the content of the defining characteristics of the IGE diagnosis in adult patients in emergency care, since the Headache upon waking indicator did not show enough score to be validated (score $=0,32$ ).

Another indicator to be highlighted is Visual disturbances which, although it reached the parameter to be considered adequate, the descriptive test level was very close to identifying that the proportion of agreement of the judges was less than $85 \%(p=0.057)$, which corroborated with the literature ${ }^{(24)}$. Bearing in mind that the definition of this indicator seems to be in tune with the IGE diagnosis, although few studies have proved its importance, it was decided to keep it 
as an indicator to verify whether there is in fact a relationship between them when subjected to clinical testing.

Additionally, indicators present in NANDA-( ${ }^{(4)}-$ Abnormal arterial blood gases and Abnormal breathing pattern were identified, in the literature, as belonging to other clinical indicators. For example, Abnormal arterial blood gases were considered at abnormal arterial pH, Hypoxia and Hypoxemia. As for the indicator Abnormal breathing pattern, there was a similarity with the diagnosis under study. In addition, the same can be understood among the Dyspnea, Tachypnea and Bradypnea indicators. Thus, it is suggested that these indicators present in the current version of NANDA- ${ }^{(4)}$ be removed from the next version, so that confusions are avoided during the diagnostic inference of IGE.

\section{$\square$ CONCLUSION}

The present study assessed 22 indicators, of which only one was not considered relevant for the diagnosis of IGE. Headache upon waking was the indicator that, according to the judges' assessment, does not correspond to a safe manifestation to identify the diagnosis under study. In addition, although the other indicators were considered relevant to the occurrence of IGE and their definitions were adequately clear and precise, some of these definitions have been adapted in their writing to better represent the indicator in relation to the diagnosis.

The knowledge by the nurse about clinical indicators of IGE may help in the process of diagnostic inference since such concepts represent the individual's functional weakness in performing gas exchanges. This fact is important in the current situation of public health worldwide, with regard to the pandemic of the new coronavirus. Patients with severe cases of COVID-19 presented clinical indicators listed for IGE as hypoxia, hypercapnia, cyanosis, and hypoxemia, suggesting a deficiency during the process of pulmonary gases exchange. Thereby, the nurse will be able to use specific interventions for this nursing phenomenon, making directed care, individualized and objective for the real clinical situation of the patient. Such measures aim to maintain the patient and aim to improve the clinical status.

Some difficulties were present in the development of the present study, such as low adherence and the delay in the return of assessments by the judges, causing the need to extend the data collection period. In addition, it should be noted the low adherence of judges with a higher instruction level - PhD. A sample with a higher level of knowledge, which is expected from those judges with a doctorate, can provide a more careful analysis of the necessary elements for the safe diagnostic inference of
IGE. Another limitation of the study refers to the gap in the literature regarding studies on content analysis of the IGE diagnosis, which compromises the comparison between the results of the present study.

In view of the above, caution is recommended regarding the findings of the present study, as well as other research on the theme, by which it is possible to test the occurrence of clinical indicators of IGE in specific populations, such as clinical validation studies of nursing diagnoses.

\section{REFERENCES}

1. Wu Z, McGoogan JM. Characteristics of and important lessons from the coronavirus disease 2019 (COVID-19) outbreak in China: summary of a report of 72314 case from the Chinese Center for Disease Control and Prevention. JAMA 2020;323(13):1239-42. doi: https://doi.org/10.1001/jama.2020.2648

2. Jonsdottir HR, Dijkman R. Coronaviruses and the human airway: a universal system for virus-host interaction studies. Virol J. 2016;13:24. doi: https://doi. org/10.1186/s12985-016-0479-5

3. World Health Organization (CH). Coronavirus disease 2019 (COVID-19): Situation Report - 70 [Internet]. Geneva: WHO; 2020 [cited 2020 jun 10]. Available from: https://www.who.int/docs/default-source/coronaviruse/ situation-reports/20200330-sitrep-70-covid-19.pdf?sfvrsn=7e0fe3f8_2

4. Herdman TH, Kamitsuru S. Diagnósticos de Enfermagem da NANDA-l: definições e classificações 2018-2020. 11. ed. Porto Alegre: Artmed; 2018.

5. Pascoal LM, Lopes MVO, Silva VM, Chaves DBR, Beltrão BA, Nunes MM, et al. Clinical differentiation of respiratory nursing diagnoses among children with acute respiratory infection. J Pediatr Nurs. 2016;31(1):85-91. doi: https://doi. org/10.1016/j.pedn.2015.08.002

6. Pascoal LM, Lopes MVO, Chaves DBR, Beltrão BA, Nunes MM, Silva VM, et al. Impaired gas exchange: prognostic clinical indicators of short-term survival in children with acute respiratory infection. Int J Nurs Knowl. 2019;30(2):87-92. doi: https://doi.org/10.1111/2047-3095.12203

7. Nascimento JN, Pascoal LM, Sousa VEC, Nunes SFL, Lima PM Neto, Santos FDRP. Asociación entre diagnósticos e intervenciones de enfermeras en pacientes sometidos a cirugía torácica oabdominal superior. Enferm Clin. 2020; 30(1):31-6. doi: https://doi.org/10.1016/j.enfcli.2018.12.003

8. Lopes MVO, Silva VM, Araújo TL. Methods for establishing the accuracy of clinical indicators in predicting nursing diagnoses. Int J Nurs Knowl. 2012;23(3):134-9. doi: https://doi.org/10.1111/j.2047-3095.2012.01213.x

9. Pascoal LM. Validação diferencial dos diagnósticos de enfermagem Desobstrução Ineficaz de Vias Aéreas, Padrão Respiratório Ineficaz e Troca de Gases Prejudicada [tese]. Fortaleza (CE): Universidade Federal do Ceará; 2015 [cited 2020 Jun 10]. Available from: http://www.repositorio.ufc.br/bitstream/ riufc/12558/1/2015_tese_Impascoal.pdf

10. Delgado-Rico E, Carretero-Dios H, Ruch W. Content validity evidences in Test development: an applied perspective. Int J Clin Health Psych. 2012;12(3):44960. doi: https://doi.org/10.5167/uzh-64551

11. Lopes MVO, Silva VM, Araújo TL. Validation of nursing diagnosis: challenges and alternatives. Rev Bras Enferm. 2013;66(5):649-55. Portuguese. doi: https://doi. org/10.1590/S0034-71672013000500002

12. Polit DF, Beck CT. Essentials of nursing research: appraising evidence for nursing practice. 9th ed. Philadelphia (PA): Lippincott Williams \& Wilkins; 2019. 
13. Huang C, Wang Y, Li X, Ren L, Zhao J, Hu Y, et al. Clinical features of patients infected with 2019 novel coronavirus in Wuhan, China. Lancet. 2020;395(10223):P497-506. doi: https://doi.org/10.1016/ S0140-6736(20)30183-5

14. Liu X, Liu X, Xu Y, Xu Z, Huang Y, Chen S, et al. Ventilatory ratio in hypercapnic mechanically ventilated patients with COVID-19 associated ARDS. Am J Respir Crit Care Med. 2020;201(10):1297-9. doi: https://doi.org/10.1164/ rccm.202002-0373LE

15. Geier MR, Geier DA. Respiratory conditions in coronavirus disease 2019 (COVID-19): important considerations regarding novel treatment strategies to reduce mortality. Med Hypotheses. 2020;140:109760. doi: https://doi. org/10.1016/j.mehy.2020.109760

16. Cespedes M, Souza, JCR. Sars-CoV-2: a clinical update - II. Rev Assoc Med Brasil. 2020;66(4):547-57. doi: https://doi.org/10.1590/1806-9282.66.4.547

17. Zhang Y, Cao W, Xiao M, Li Y, Yang Y, Zhao J, et al. [Clinical and coagulation characteristics of 7 patients with critical COVID-2019 pneumonia and acroischemia]. Chin J Hematol. 2020;41(04):302-7. Chinese. doi: https://doi. org/10.3760/cma.j.jissn.0253-2727.2020.0006

18. Xie J, Covassin N, Fan Z, Singh P, GaoW, Li G, etal. Association between hypoxemia and mortality in patients with COVID-19. Mayo Clin Proc. 2020;95(6):1138-47. doi: https://doi.org/10.1016/j.mayocp.2020.04.006

\section{- Acknowledgments:}

Foundation for the Support of Research and Scientific and Technological Development of Maranhão (Fundação de Amparo à Pesquisa e ao Desenvolvimento Científico e Tecnológico do Maranhão - FAPEMA).

\section{- Corresponding author:}

Lívia Maia Pascoal

Email: livia_mp@hotmail.com
19. Lo Mauro A, Aliverti A. Physiology of respiratory disturbances in muscular dystrophies. Breathe (Sheff.). 2016;12(4):318-27. doi: https://doi. org/10.1183/20734735.012716

20. Suzuki K, Miyamoto M, Miyamoto T, Numao A, Suzuki S, Sakuta H, et al. Sleep apnoea headache in obstructive sleep apnoea syndrome patients presenting with morning headache: comparison of the ICHD-2 and ICHD-3 beta criteria. J Headache Pain. 2015;16:56. doi: https://doi.org/10.1186/s10194-015-0540-6

21. Chiu YC, Hu HY, Lee FP, Huang HM. Tension-type headache associated with obstructive sleep apnea: a nationwide population-based study. J Headache Pain. 2015;16:34. doi: https://doi.org/10.1186/s10194-015-0517-5

22. Boostani R, Rezaeitalab F, Pourmokhtari B, Ghahremani A. Sleep apnea headaches. Rev Clin Med. 2016;3(1):1-3. doi: https://doi.org/10.17463/ RCM.2016.01.001

23. Rocha E, Carneiro EM. Benefits and complications of noninvasive mechanical ventilation for acute exacerbation of chronic obstructive pulmonary disease. Rev Bras Ter Intensiva. 2008;20(2):184-9. doi: https://doi.org/10.1590/ S0103-507X2008000200012

24. Pascoal LM, Lopes MVO, Chaves DBR, Beltrão BA, Silva VM, Monteiro FPM. Impaired gas exchange: accuracy of defining characteristics in children with acute respiratory infection. Rev Lat-Am Enfermagem. 2015;23(3):491-9. doi: https://doi.org/10.1590/0104-1169.0269.2581

\section{Associate editor:}

Graziella Badin Aliti

Editor-in-chief:

Received: 05.11.2020

Maria da Graça Oliveira Crossetti 